\title{
Nonlinear Varying-Network Magnetic Circuit Analysis of Consequent-Pole Permanent-Magnet Motor for Electric Vehicles
}

\author{
Hui Wang ${ }^{1 \oplus}$, Kwok Tong Chau ${ }^{1, * \mathbb{C}}$, Christopher H. T. Lee ${ }^{2}$, C. C. Chan ${ }^{1}$ and Tengbo Yang ${ }^{1}(\mathbb{D}$ \\ 1 Department of Electrical and Electronic Engineering, The University of Hong Kong, Hong Kong, China; \\ huiwang3@eee.hku.hk (H.W.); ccchan@eee.hku.hk (C.C.C.); yangtb@eee.hku.hk (T.Y.) \\ 2 School of Electrical and Electronic Engineering, Nanyang Technological University, Singapore 639798, \\ Singapore; chtlee@ntu.edu.sg \\ * Correspondence: ktchau@eee.hku.hk
}

Citation: Wang, H.; Chau, K.T.; Lee, C.H.T.; Chan, C.C.; Yang, T. Nonlinear Varying-Network Magnetic Circuit Analysis of Consequent-Pole Permanent-Magnet Motor for Electric Vehicles. World Electr. Veh. J. 2021, 12, 254. https://doi.org/10.3390/ wevj12040254

Academic Editor: Hui Yang

Received: 12 October 2021

Accepted: 29 November 2021

Published: 1 December 2021

Publisher's Note: MDPI stays neutral with regard to jurisdictional claims in published maps and institutional affiliations.

Copyright: () 2021 by the authors. Licensee MDPI, Basel, Switzerland. This article is an open access article distributed under the terms and conditions of the Creative Commons Attribution (CC BY) license (https:// creativecommons.org/licenses/by/ $4.0 /)$.

\begin{abstract}
To conserve rare earth resources, consequent-pole permanent-magnet (CPPM) machine has been studied, which employs iron-pole to replace half PM poles. Meanwhile, to increase fluxweakening ability, hybrid excitation CPPM machine with three-dimensional (3-D) flux flow has been proposed. Considering finite element method (FEM) is time-consuming, for the analysis of the CPPM machine, this paper presents a nonlinear varying-network magnetic circuit (NVNMC), which can analytically calculate the corresponding electromagnetic performances. The key is to separate the model of CPPM machine into different elements reasonably; thus, the reluctances and magnetomotive force (MMF) sources in each element can be deduced. While taking into account magnetic saturation in the iron region, the proposed NVNMC method can accurately predict the 3-D magnetic field distribution, hence determining the corresponding back-electromotive force and electromagnetic power. Apart from providing fast calculation, this analytical method can provide physical insight on how to optimize the design parameters of this CPPM machine. Finally, the accuracy of the proposed model is verified by comparing the analytical results with the results obtained by using FEM. As a result, with so many desired attributes, this method can be employed for machine initial optimization to achieve higher power density.
\end{abstract}

Keywords: varying-network magnetic circuit; consequent-pole permanent-magnet machine; threedimensional field distribution

\section{Introduction}

Hybrid excitation synchronous machines (HESM) incorporate both permanent magnets and field winding for field excitation [1]. By employing these two excitation field sources, the flux weakening capability and hence the speed range can be significantly improved [2]. According to the arrangement of PM and excitation coils, HESM can be represented as series hybrid excitation (SHE) and parallel hybrid excitation (PHE) machines [3].

For PHE machines, the excitation fluxes produced by PMs and field winding have different trajectories [4]. Therefore, the risk of irreversible demagnetization of the PMs can be avoided. Among those PHE machines, the consequent-pole PM (CPPM) machine possesses inherent field weakening capability [5]. The PM and field-winding are housed in the rotor and stator separately. Therefore, air-gap flux can be regulated, and the demagnetization risk can be avoided. Meanwhile, as the field control winding is housed in the stator, the brushes or slip rings can be eliminated. Besides, compared with traditional PM machine, less rare-earth PM is required, as CPPM machine employed iron-pole to replace half of PM poles [6], as shown in Figure 1.

To improve machine's power density and torque density, various design methods have been proposed in CPPM machines [7,8]. For example, in [9], the fundamental of the air-gap flux density distribution can be improved by optimizing the width of PMs. 


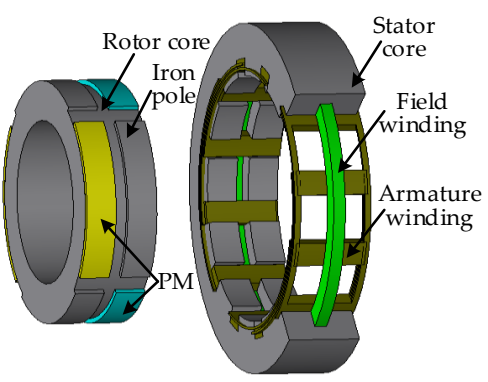

(a)

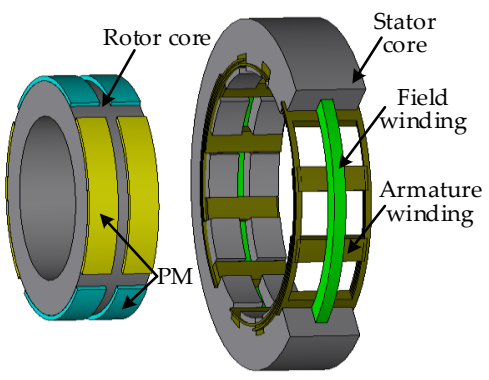

(b)

Figure 1. Machine Structure. (a) Consequent-pole PM machine. (b) PM machine.

In these papers, the finite element method (FEM) is generally employed. Thanks to the enormous improvement in digital computing, FEM has developed into a mature modeling technique, capable of accurately predicting motor performance. Meanwhile, many available FEM software packages, such as JMAG [4], Ansys [10] and MotorSolve [11], have largely simplified the implementation. However, compared to the analytical models, FEM is very time-consuming, especially for three-dimensional (3-D) motors [12]. Therefore, analytical methods, such as nonlinear varying-network magnetic circuit (NVNMC) method and Fourier modeling method, are proposed for the initial design. Based on analytical equations and often tuned empirically, analytical methods can provide comparatively accurate prediction of the motor performance, and take the definite advantages of fast computation and simple implementation [13]. Based on previous research results, a comparison between FEM, Fourier modeling method and NVNMC is listed in Table 1. It can be seen that NVNMC model is more suitable for saturation condition than Fourier modeling method [13]; thus, the former one is employed in this paper. However, the available NVNMC model is ill-suited for advanced machines with 3-D flux flow.

The purpose of this paper is to develop the NVNMC model of CPPM machines, hence assessing their electromagnetic performances, including the magnetic field distribution and back-electromotive force (EMF). The two-dimensional (2-D) NVNMC for CPPM machines is presented, and magnetic saturation and flux leakage is considered. This paper considers, for the first time, the use of 2-D NVNMC model to predict the performance of 3-D machine. In order to verify the accuracy of the proposed model, the NVNMC results and FEM results are quantitatively compared. Consequently, the proposed NVNMC method can be employed as a tool to optimize the CPPM machine in future study.

In Section 2, the NVNMC model of CPPM machine in [14] will be described. Then, the model is analyzed in Section 3. Section 4 will be devoted to solving this model. Then, the results will be presented in Section 5, and these are compared with FEM results. Finally, a conclusion will be drawn in Section 6 .

Table 1. Comparison of different analysis methods.

\begin{tabular}{|c|c|c|}
\hline Method & Application Cases & Feature \\
\hline $\begin{array}{c}\text { Finite element } \\
\text { method }\end{array}$ & $\begin{array}{ll}\text { - } & \text { Hybrid-excited machine with JMAG [4] } \\
\text { - } & \text { SR motor and FSPM motor with Ansys [10] } \\
\text { - } & \text { Variable Flux machine with MotorSolve [11] }\end{array}$ & $\begin{array}{l}\text { - } \\
\text { - } \\
\text { - } \\
\text { - } \\
\text { Magailable for 2-D and 3-D machines } \\
\text { Time-consuming }\end{array}$ \\
\hline $\begin{array}{l}\text { Fourier modeling } \\
\text { method }\end{array}$ & $\begin{array}{ll}- & \text { FSPM Machine [15] } \\
- & \text { Surface-Mounted PM machine [16] }\end{array}$ & $\begin{array}{ll}- & \text { Generally for 2-D } \\
- & \text { Suitable for periodic structures [17] } \\
\text { - } & \text { Time-saving }\end{array}$ \\
\hline $\begin{array}{l}\text { Magnetic circuit } \\
\text { analysis }\end{array}$ & $\begin{array}{ll}- & \text { DSPM machine [18] } \\
\text { - } & \text { FSPM machine [19] } \\
\text { - } & \text { Rotor-segmented axial-field SRM [12] } \\
\text { Transverse-flux brushless double-rotor machine [20] }\end{array}$ & $\begin{array}{ll}\text { - } & \text { Generally for 2-D } \\
\text { - } & \text { Suitable for saturation condition [17] } \\
\text { - } & \text { Providing physical insight for machine design [13] } \\
\text { implementation [15] }\end{array}$ \\
\hline
\end{tabular}




\section{NVNMC Model}

Figure 1a shows the structure of a three-phase 12-slot 4-pole CPPM machine. It should be mentioned that the rotor has radially magnetized bipolar PMs distributed alternatively in the circumferential direction, and other parts are iron poles (also called rotor tooth in this paper) [6]. Due to symmetry, this CPPM machine can be considered as two 6/2-pole machines. Hence, the modeling is needed only for the 6/2-pole machine.

Although the machine involves 3-D flux flow, the corresponding 2-D NVNMC model is depicted in Figure 2. The key is to translate the 3-D flux path into a 2-D NVNMC model properly, namely the upper half of rotor is drawn inside the rotor yoke, while the upper half of stator is drawn outside the stator yoke.

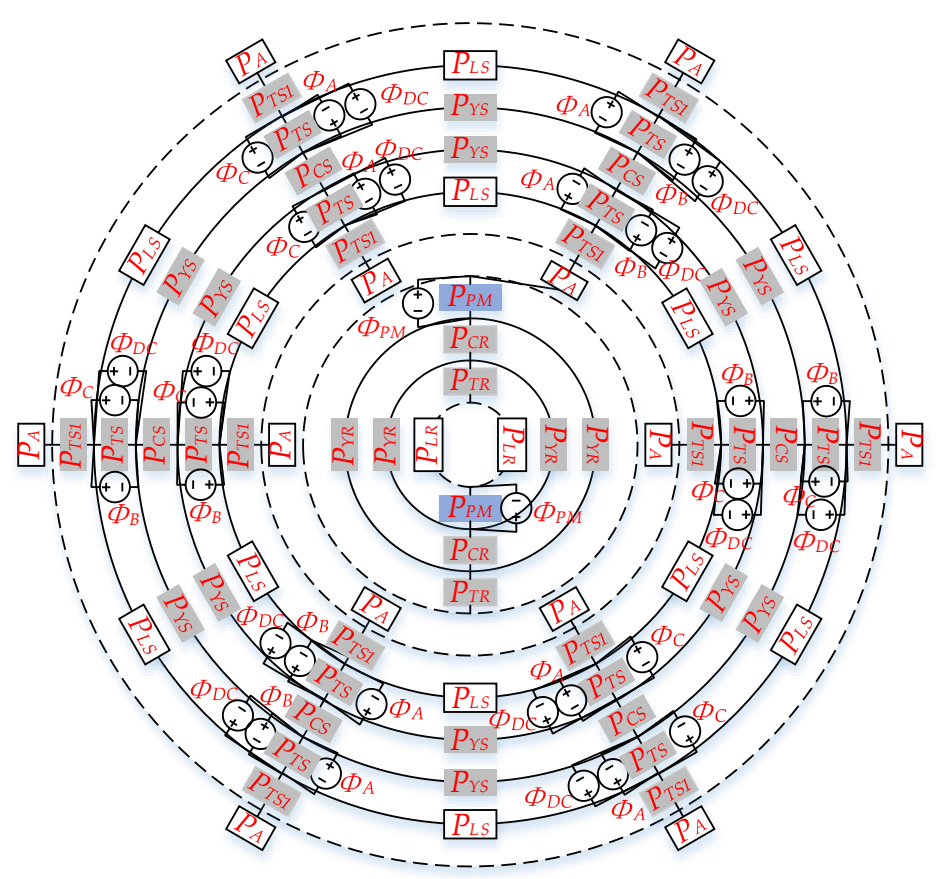

Figure 2. NVNMC model of CPPM machine.

In this model, $P_{T R}, P_{Y R}, P_{C R}, P_{T S 1}, P_{T S}, P_{Y S}$, and $P_{C S}$ are the permeances of rotor tooth, rotor yoke, rotor consequent-yoke, stator inner tooth, stator outer tooth, stator yoke, and stator consequent-yoke, respectively, which vary with the nonlinear saturation in the corresponding magnetic paths, while $P_{P M}, P_{L R}$, and $P_{L S}$ are the permeances of $P M$, rotor tooth-to-PM leakage flux, and stator tooth-to-tooth leakage flux, respectively, which are of constant permeability [18].

It should be emphasized that although there is only one $P_{A}$ module drawn in front of each stator tooth in the model, it can be considered as each stator tooth having two $P_{A}$ modules connecting the PM and rotor tooth. So, there is a total of $24 P_{A}$ modules in this model, and apparently, the value of some $P_{A}$ modules could become zero when the rotor is rotating. Besides, the connection lines between the outer $P_{A}$ and inner PM, as well as rotor teeth, are omitted in this figure.

In addition, $\Phi_{P M}, \Phi_{A}, \Phi_{B}, \Phi_{C}$ and $\Phi_{D C}$ represent the magnetic flux source (MFS) of the $\mathrm{PM}$, phase $\mathrm{A}$ winding, phase $\mathrm{B}$ winding, phase $\mathrm{C}$ winding and field winding, respectively. It should be noted that the armature MFS supplied by phase A, phase $B$, and phase $C$ winding is represented by eight $\Phi_{A}, \Phi_{B}$, and $\Phi_{C}$ modules separately, while the MFS provided by DC winding is represented by twelve $\Phi_{D C}$ modules. 


\section{Model Analysis}

In NVNMC model, the magnetic field distribution is highly related to the geometry of the PM and the reluctance of its path. In this case, the magnetic flux source, the air-gap, and magnet reluctances are the most important values.

The basic equation which governs the permeance of each element is given by [21]

$$
P=\left\{\begin{array}{lr}
\mu_{0} \frac{b \times h}{l} & \text { (air) } \\
\mu_{\text {iron } \frac{b \times h}{l}} & \text { (silicon steel) }
\end{array}\right.
$$

where $\mu_{0}$ and $\mu_{\text {iron }}$ are the permeability of air and iron region, while $b, h$, and $l$ are the width, height, and length of the element.

Although most elements' permeances can be easily acquired from (1), the calculations of main air-gap, stator and rotor cores are difficult and subtle. Hence, the calculation procedure for these parts is detailed in the following.

\subsection{The Permeance of Air-Gap}

As the permeance of air-gap is varying with the rotor position, the whole mechanical period is separated into seven regions, which can be defined as Region $10 \leq \theta \leq \theta_{1}$, Region $2 \theta_{1}<\theta \leq \theta_{2}, \ldots$, and Region $7 \theta_{6}<\theta$, where $\theta$ is the angle between the central lines of rotor and stator teeth. As depicted in Figure $3, \theta_{1}$ to $\theta_{6}$ can be calculated as $\theta_{1}=1 / 2 \times\left(\beta_{r}\right.$ $\left.-\tau_{s}\right), \theta_{2}=1 / 2 \times\left(\beta_{r}-\beta_{s}\right), \theta_{3}=1 / 2 \times\left(\tau_{r}-\beta_{s}\right), \theta_{4}=1 / 2 \times\left(\beta_{r}+\beta_{s}\right), \theta_{5}=1 / 2 \times\left(\beta_{r}+\tau_{s}\right)$, and $\theta_{6}=1 / 2 \times\left(\tau_{r}+\tau_{s}\right)$, where $\tau_{r}$ and $\tau_{s}$ are the pole pitches of rotor and stator, and $\beta_{r}$ and $\beta_{s}$ are the tooth arc of rotor and stator.

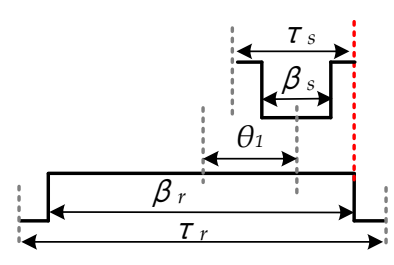

(a)

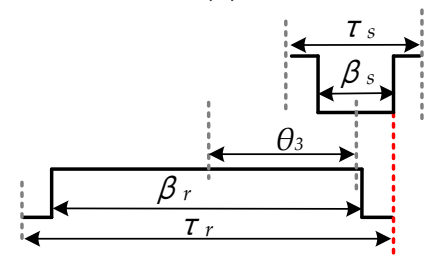

(c)

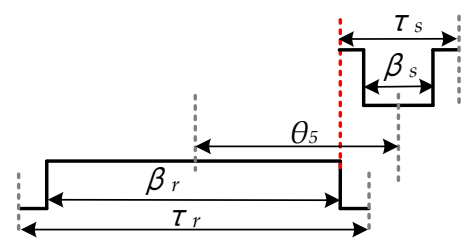

(e)

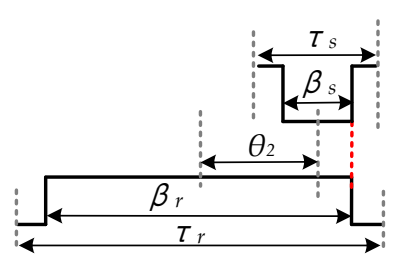

(b)

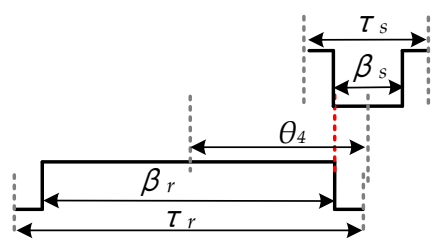

(d)

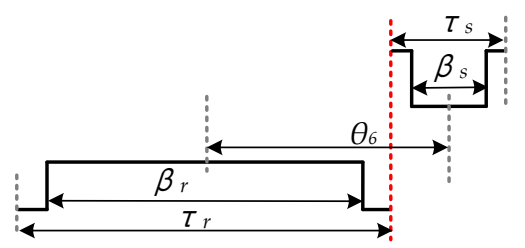

(f)

Figure 3. Rotor positions at different regions: (a) Region one; (b) Region two; (c) Region three; (d) Region four; (e) Region five; (f) Region six.

By employing the calculation method in [18], the air-gap permeance in each region can be calculated. It should be noted that the permanence between rotor yoke and stator pole should not be considered when calculating the $P_{A}$ between PM and stator pole. In this paper, $P_{A}-\theta$ curve, the relationship between air-gap permeance and rotor angle, is shown in Figure 4. 


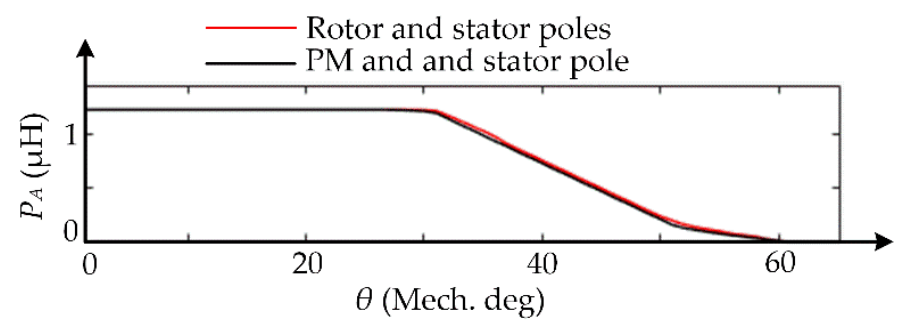

Figure 4. Relationship between air-gap permeance and rotor position.

\subsection{The Permeance of Tooth, Yoke, and Consequent-Yoke}

Figure 5a,b show the field distribution of the stator and rotor core separately. In order to analyze these two iron regions, the stator is separated as stator tooth (including $P_{T S 1}$ and $\left.P_{T S}\right)$, stator yoke, and stator consequent-yoke, so that the corresponding magnetic field distributions can be seen as radial, circumferential, and axial directions, respectively [22]. Similarly, the magnetic field distributions in the rotor tooth, rotor yoke, and rotor consequent-yoke are separated in accordance with the relevant parts of the stator.

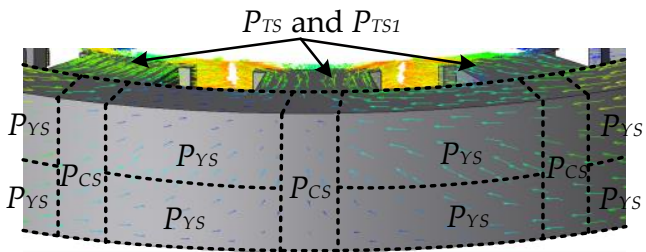

(a)

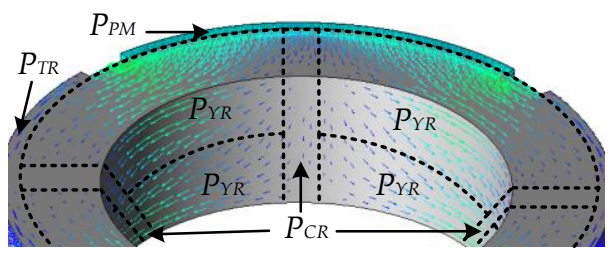

(b)

Figure 5. Separation of stator and rotor core: (a) One stator segment; (b) One rotor segment.

To separate the stator and rotor core preciously, the widths of $P_{C R}$ and $P_{C S}$, as well as the lengths of $P_{Y R}$ and $P_{Y S}$, are specified based on FEM [18], and change dynamically with field current. But it should be mentioned that the FEM simulation only needs to run a few angles to get the widths of $P_{C R}$ and $P_{C S}$, thus the time can be saved. Then, as the magnetic field distribution in each element is simplified as one-directional [23], (1) can be employed to calculate the $P_{T R}, P_{Y R}, P_{C R}, P_{T S 1}, P_{T S}, P_{Y S}$, and $P_{C S}$.

\subsection{The Magnetic Flux Source}

The magnetomotive force (MMF) obtained from PM can be simplified as [24]

$$
F_{P M}=B_{r} h_{m} / \mu_{0}
$$

where $h_{m}$ and $B_{r}$ is the thickness and the remanence of PM, separately.

Therefore, the MFS of PM, namely $\Phi_{P M}$, can be acquired by

$$
\Phi_{P M}=F_{P M} P_{P M}
$$

where $P_{P M}$ is the permeance of $P M$, which can be obtained through (1).

The armature windings are formed by symmetrical three-phase windings. Taking phase $C$ winding as an example, the MMF can be acquired through [25]

$$
F_{C}=N_{C} I_{C}
$$

where $N_{C}$ and $I_{C}$ are the number of turns and the current of phase $C$ winding, respectively.

It should be noticed that as the armature field flows as Figure 6 shows, the whole MMF is evenly distributed to every stator tooth near the armature windings.

$$
\Phi_{C}=F_{C} P_{T S} / 2
$$




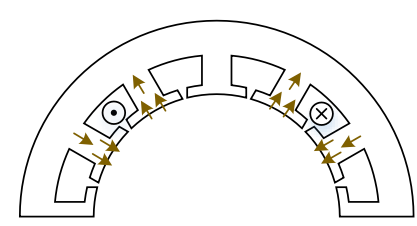

Figure 6. Armature field excited by phase $C$ winding.

For the field-winding, it is formed by DC coils. The MMF of this winding can be acquired through [25]

$$
F_{D C}=N_{D C} I_{D C}
$$

where $N_{D C}$ and $I_{D C}$ are the numbers of turns and the current of DC windings, separately.

It should be emphasized that the flux excited by DC winding flows from one stator tooth to another axially adjacent tooth through the stator consequent-yoke. Therefore, the whole MMF is evenly distributed to every stator tooth.

The basic equation which governs the MFS of each stator tooth is given by [25]

$$
\Phi_{D C}=F_{D C} P_{T S} / 2
$$

\section{Magnetic Circuit Equations}

\subsection{Establishment of the Magnetic Circuit Equations}

The nodal analysis and Kirchhoff's Law are employed to establish the magnetic circuit, the basic equation which governs the whole NVNMC model is given by [24]

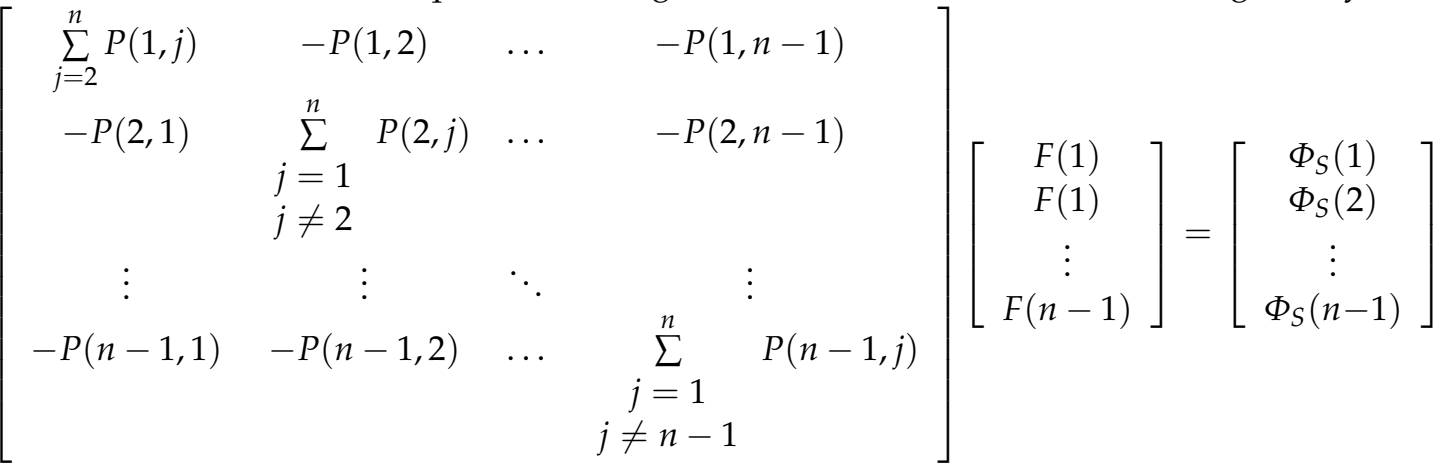

where

$n$ number of nodes;

$P(i, j)$ for $i, j=1,2, \ldots, n-1$, is the permeance of branch, which connects node $i$ and $j$;

$F(i)$ for $i=1,2, \ldots, n-1$, is the node magnetic potential;

$\Phi_{s}(i)$ for $i=1,2, \ldots, n-1$, is the node magnetic flux source.

It should be mentioned that the number of independent nodes in this model is $n-1$, and the magnetic potential for node $n$ is zero.

\subsection{Calculation of the Magnetic Circuit Equations}

As the magnetic circuit equation is established in the former section, the magnetic potential of all nodes can be obtained by [26]

$$
F=P^{-1} \cdot \Phi_{S}
$$

where $P, F$, and $\Phi_{S}$ are the node permeance matrix, node magnetic vector potential, and node magnetic flux source, respectively.

Then the magnetic flux in each branch can be deduced by [18]

$$
\Phi(i, j)=[F(i)-\mathrm{F}(j)] / P(i, j)
$$

where $\Phi(i, j)$ is the magnetic flux flows branch, which connects nodes $i$ and $j$. 
However, it should be noticed that the permeance of each branch is varying; i.e., the permeance of the main air-gap varies as the rotor rotates, and the permeance of stator and rotor element varies as the flux density changes. Different from air-gap permeance, which can be acquired by employing an appropriate $P_{A}-\theta$ curve (depicted in Figure 4), the precise permeance of the iron region can only be obtained by solving the NVNMC model iteratively [17]. In detail, by employing a reliable initial value of iron permeability, such as $3500 \mu_{0}$, the magnetic flux in each iron element can be acquired through (10), as well as the magnetic flux density can be obtained. Therefore, the permeability of this region can be updated through the material's $B-H$ curve.

Nevertheless, directly employing the new permeability in (8) is ill-suitable, because the iteration procedure could be an endless loop in this case. For example, if the flux density acquired in $(k-1)$ th step is higher than $2 \mathrm{~T}$, then the permeability $\mu^{k-1}$ iron would be relatively small, such as $100 \mu_{0}$, then with this value, the flux density acquired in $k$ th step could be much lower, such as $1 \mathrm{~T}$, and the corresponding permeability, namely $\mu^{k}{ }_{\text {iron }}$, could be $4000 \mu_{0}$, so the flux density acquired in $(k+1)$ th step could be $2 \mathrm{~T}$ again. Hence, to avoid this problem, the permeability for $k$ th iteration can be obtained by [24]

$$
\mu_{\text {iron }}^{k}=p \mu_{\text {iron }}^{k-1}+(1-p) \mu_{\text {iron }}^{k}
$$

where $p$ is a damping factor that is between 0 to 1 , and is varying with the iteration steps. For example, damping factor could be $0.3,0.1$ and 0.02 in the first, second and last ten iterations. Compared with fixed damping factor, the precise result can be acquired quickly with varying damping factor. Taking the stator tooth as an example, the permeance of stator tooth is shown in Figure 7. It can be observed that this model cannot acquire precise result when damping factor is 0.25 , and it takes a long time to solve the NVNMC model when damping factor is 0.02 . However, the precise result can be acquired quickly with varying damping factor.

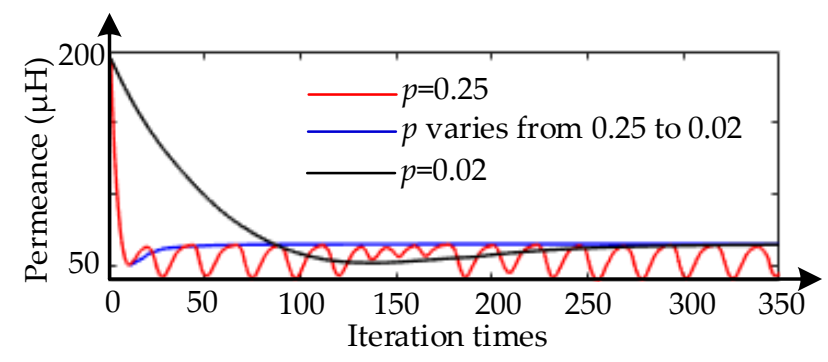

Figure 7. Permeance of rotor tooth with different damping factors.

When the discrepancy between $\mu^{k-1}$ iron and $\mu^{k}$ iron is tolerable, the iteration can be finished, and the precise solution of this NVNMC model can be acquired [23].

\section{Results and Discussion}

Based on the aforementioned solving procedure, major parameters of the CPPM machine are determined as listed in Table 2, and marked in Figure 8, which will be used for predicting electromagnetic performance. It should be noted that the method of determining winding turns is given in [11]. Besides, the results acquired by NVNMC models and 3-D FEM are compared in this section. 
Table 2. Machine parameters.

\begin{tabular}{cc}
\hline Item & Value \\
\hline Number of phases & 3 \\
Rotor inner radius $\left(R_{I R}\right)$ & $35 \mathrm{~mm}$ \\
Rotor outer radius $\left(R_{O R}\right)$ & $63.5 \mathrm{~mm}$ \\
Rotor tooth height $\left(L_{I P}\right)$ & $2.5 \mathrm{~mm}$ \\
Rotor tooth arc $\left(\beta_{r}\right)$ & $80^{\circ}$ \\
PM thickness $\left(L_{P M}\right)$ & $2.5 \mathrm{~mm}$ \\
Air-gap length $\left(L_{A}\right)$ & $0.5 \mathrm{~mm}$ \\
The thickness of PM $\left(L_{P M}\right)$ & $2.5 \mathrm{~mm}$ \\
Stator inner radius $\left(R_{I S}\right)$ & $64 \mathrm{~mm}$ \\
Stator outer radius $\left(R_{O S}\right)$ & $100 \mathrm{~mm}$ \\
Stator tooth height $\left(L_{T S}\right)$ & $16.5 \mathrm{~mm}$ \\
Stator tooth arc $\left(\beta_{s 1}, \beta_{s 2}\right)$ & $10^{\circ}, 7.5^{\circ}$ \\
Height of motor $\left(H_{M}\right)$ & $46 \mathrm{~mm}$ \\
Height of DC winding $\left(H_{D C}\right)$ & $6 \mathrm{~mm}$ \\
DC winding turns $\left(N_{D C}\right)$ & 35 \\
Winding turns per phase $\left(N_{A}, N_{B}, N_{C}\right)$ & $130,130,130$ \\
Residual magnetism of $P M$ & $1.4 \mathrm{~T}$ \\
Rotor speed & $1800 \mathrm{rpm}$ \\
\hline
\end{tabular}

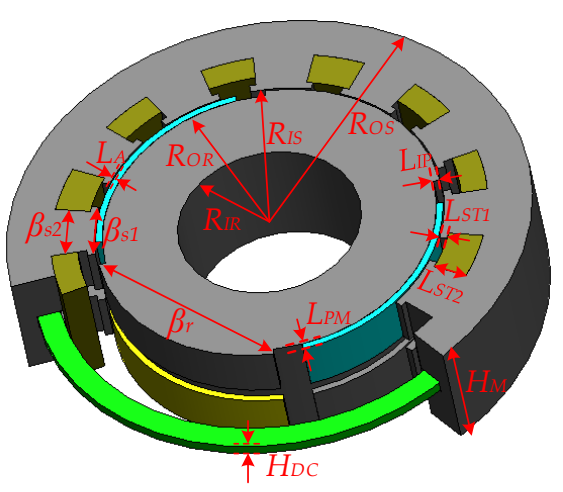

Figure 8. System parameters.

\subsection{Coil Flux Linkage}

Figure 9 shows the waveforms of $\varphi_{A}$, namely the coil flux linkage of phase A. Meanwhile, the strengthening and weakening actions of the armature current are tested under different field winding currents with the value of $0 \mathrm{~A}, 10 \mathrm{~A}$ and $-10 \mathrm{~A}$. As aforementioned, hybrid excitation machines can regulate the field flux by varying the current of field winding, as shown in Figure 10. It can be seen that more flux flows at circumferential direction with $10 \mathrm{~A}$ field winding current, thus the width of $P_{C R}$ and $P_{C S}$ should be smaller; however, when the system is weakening the field flux, more flux flows at axial direction; thus, the width of $P_{C R}$ and $P_{C S}$ should be larger. But it should be mentioned that the width of $P_{C R}$ and $P_{C S}$ are not linearly related to the field current because of the saturation. Therefore, based on FEM, the widths of $P_{C R}$ and $P_{C S}$ are set as $40 \%, 25 \%$ and $55 \%$ of the stator and rotor pitches, when the field current is $0 \mathrm{~A}, 10 \mathrm{~A}$ and $-10 \mathrm{~A}$, respectively. As can be seen in Figure 9, a good agreement can be obtained between NVNMC and 3-D FEM. 


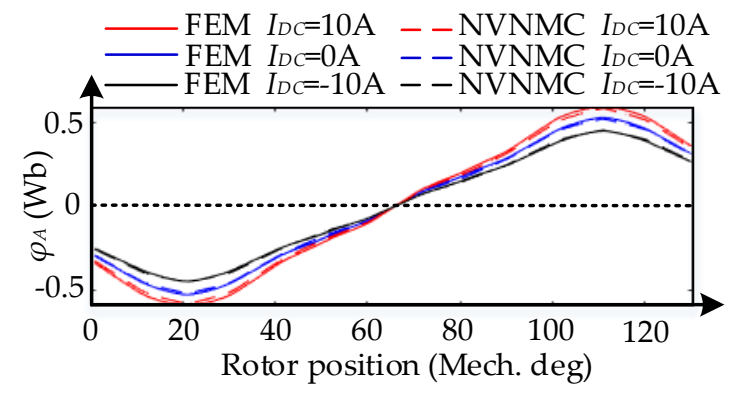

Figure 9. Flux linkage of phase A with different DC currents.

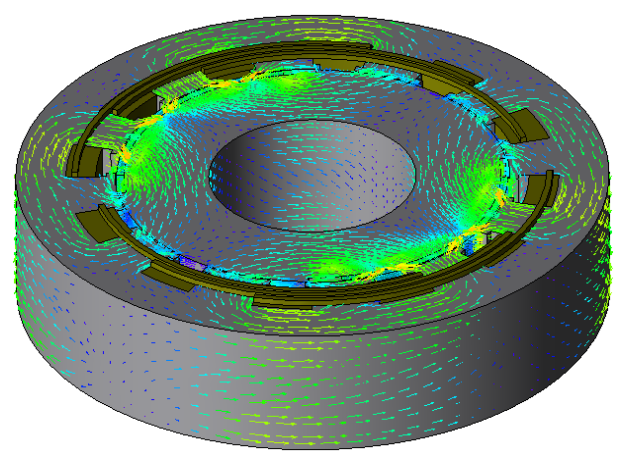

Magnetic flux density

$2 \mathrm{~T}$ (a)

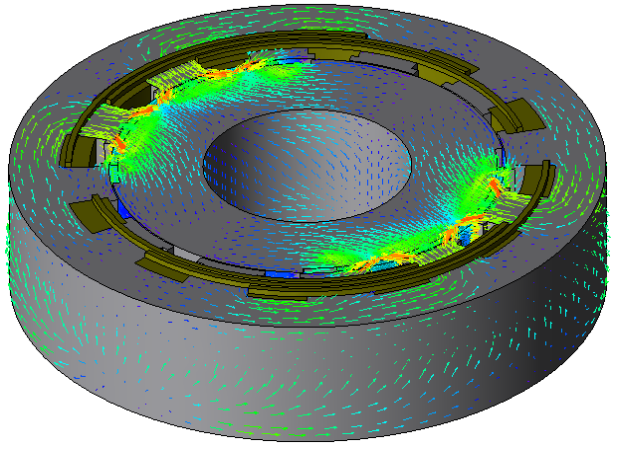

Magnetic flux density

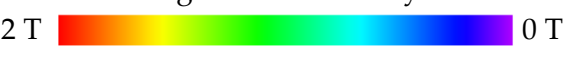

(b)

Figure 10. Magnetic vector plot of CPPM machine. (a) With 10A field current. (b) With - 10A field current.

\subsection{Back-EMF}

Figure 11 illustrates $E_{A}$, the back-EMF of phase $A$, versus rotor angle under different $I_{D C}$ and phase current, which can be acquired through [14]

$$
E_{A}=\frac{d \varphi_{A}}{d t}=\omega \frac{d \varphi_{A}}{d \theta}
$$

where $\omega$ is the angular velocity of the rotor.

As can be seen, there are few discrepancies between back-EMF calculated by the NVNMC model and FEM. Because the NVNMC method employs the simplified 2-D model to replace the 3-D machine, and the aim of this method is to rapidly predict the dynamic performance of CPPM machines with different dimensions and excitation conditions. Therefore, the degradation of accuracy is tolerable in view of the time-saving.

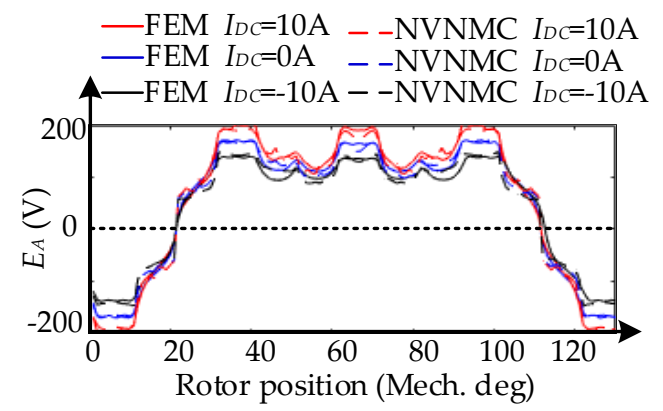

(a)

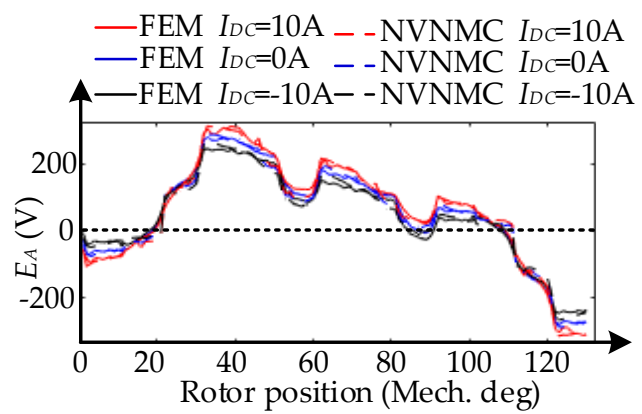

(b)

Figure 11. Back-EMF of phase A with different DC currents: (a) No phase current; (b) Feeding 3 phase AC current with the peak of $3 \mathrm{~A}$. 
However, it should be mentioned that, as shown in Figure 11a, the results of NVNMC are not so accurate in some regions. The main reason is that the air-gap magnetic field is very complicated, especially in region 5 and region $6\left(\theta_{5}<\theta\right)$, thus when the rotor turns around 30 and 110 degrees, the results of these two methods are different.

\subsection{Power}

As the winding internal resistance is very small, the copper loss is not considered in this paper. Thus, the input power of phase A and total input power be simplified as [27]

$$
P_{A}=I_{A} E_{A}
$$

and

$$
P=I_{A} E_{A}+I_{B} E_{B}+I_{C} E_{C}
$$

Figure 12 shows the variation of the input power with rotor position, fed by threephase AC current with the peak of $3 \mathrm{~A}$. As will be seen, the results acquired from NVNMC model compare well with those from 3-D FEM.

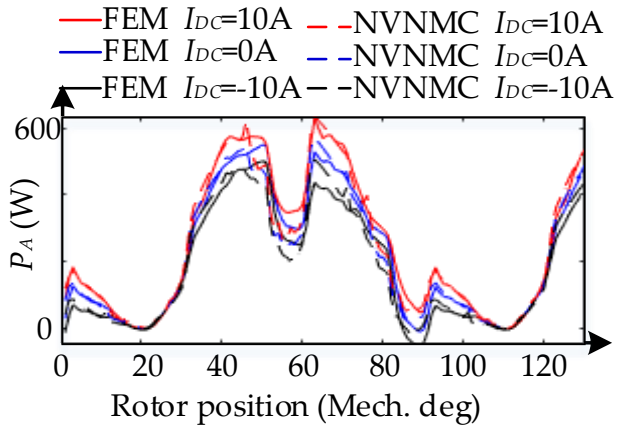

(a)

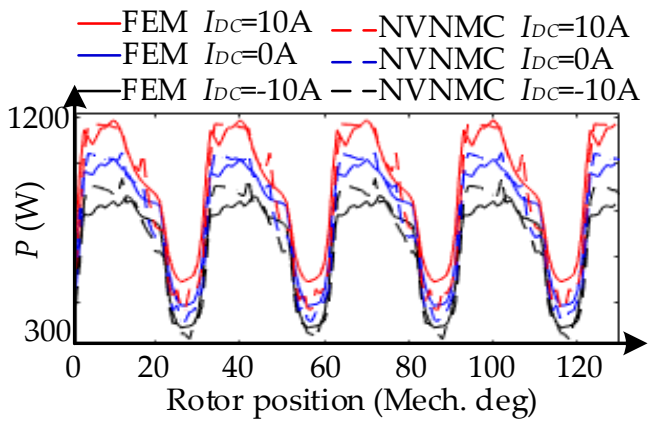

(b)

Figure 12. Input power with different DC current: (a) Power of phase A; (b) Total input power.

\subsection{Discussion}

Consistent with the theoretical analysis, the proposed NVNMC method can provide comparatively reliable results in a shorter time. As a matter of fact, the NVNMC software Matlab only needs to run $2 \mathrm{~min}$, while the FEM software JMAG needs to run $27 \mathrm{~h}$ for one cycle with same computer. Besides, it is easy to see which part is too saturated and limits the flow of machine's magnetic field; thus, we can optimize the motor parameters with physical insight.

However, the result of NVNMC method is still not as accurate as FEM method. The main reason is that the NVNMC method separates the machine into dozens of elements, and assuming the magnetic field is evenly distributed in each element to calculate the permeability. However, uneven distribution of magnetic field is unavoidable, thus it is inappropriate to calculate the permeance of each element with single permeability. In theory, this problem can be solved by separating the machine into smaller elements, as FEM method separates the machine into numerous meshes, but the running time is inevitably increased. Therefore, it is better to use NVNMC method for initial design and refine the design with FEM method, as shown in Figure 13. Considering there are too many parameters that can have an impact on the performance of the motor, how to optimize these parameters quickly and reasonably will become the future research direction of this study. 

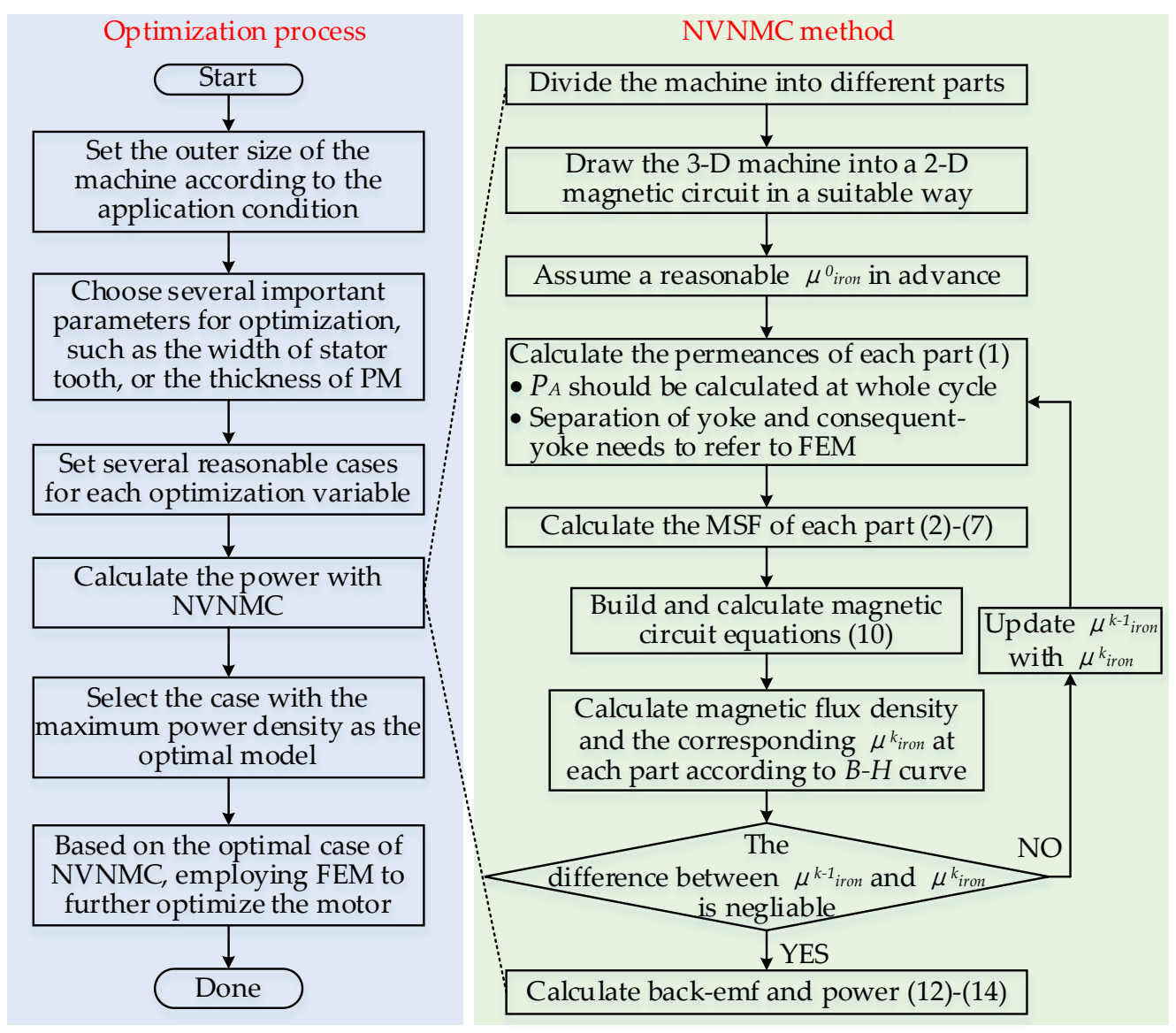

Figure 13. Flowchart of optimization.

\section{Conclusions}

In this paper, a 2-D NVNMC modeling approach has been developed to predict the electromagnetic performance, namely the air-gap field distribution and the back-EMF. The detailed calculation procedure for the permeance of main air-gap, stator, and rotor is introduced. The dynamic segmentation method is proposed, making the calculated static characteristics agree more closely with those found by FEM. Besides, the saturation is also considered, making the calculated static characteristics agree more closely with those found by FEM, and the comparisons also show that the proposed NVNMC approach offers reasonable accuracy. Furtherly, this modeling method can also be applied to other 3-D machines.

Author Contributions: The work presented in this paper is the output of the research projects undertaken by H.W. In particular, H.W. developed the topic, analyzed the results, and wrote the paper. K.T.C., C.H.T.L., C.C.C. and T.Y. helped provide guidance and resources for improving the paper. All authors have read and agreed to the published version of the manuscript.

Funding: This research was funded by a grant (Project No. 17205518) from the Hong Kong Research Grants Council, Hong Kong Special Administrative Region, China.

Institutional Review Board Statement: Not applicable.

Informed Consent Statement: Not applicable.

Data Availability Statement: Not applicable.

Conflicts of Interest: The authors declare no conflict of interest. 


\section{References}

1. Cao, L.; Chau, K.T.; Lee, C.H.T. A new parallel-hybrid-excited permanent-magnet machine with harmonic-differential effect for electric vehicles. IEEE Trans. Veh. Technol. 2020, 69, 12734-12750. [CrossRef]

2. Chau, K.T.; Jiang, C.; Han, W.; Lee, C.H.T. State-of-the-art electromagnetics research in electric and hybrid vehicles. Prog. Electromagn. Res. 2017, 159, 139-157. [CrossRef]

3. Sun, L.; Zhang, Z.; Gu, X.; Yu, L.; Li, J. Analysis of reactive power compensation effect of a new hybrid excitation brushless dc generator. IEEE Trans. Ind. Electron. 2020, 67, 3562-3572. [CrossRef]

4. Cao, L.; Chau, K.T.; Lee, C.H.T.; Lam, W.-H. Design and analysis of a new parallel-hybrid-excited machine with harmonic-shift structure. IEEE Trans. Ind. Electron. 2020, 67, 1759-1770. [CrossRef]

5. Zhao, H.; Liu, C.; Song, Z.; Liu, S. A consequent-pole pm magnetic-geared double-rotor machine with flux-weakening ability for hybrid electric vehicle application. IEEE Trans. Magn. 2019, 55, 1-7. [CrossRef]

6. Sakamoto, S.; Yokoi, Y.; Higuchi, T.; Miyamoto, Y. A study on rotor design of consequent-pole permanent magnet machines. In Proceedings of the 23rd International Conference on Electrical Machines and Systems, Hamamatsu, Japan, 24-27 November 2020.

7. Li, J.; Wang, K. A novel spoke-type pm machine employing asymmetric modular consequent-pole rotor. IEEE ASME Trans. Mechatron. 2019, 24, 2182-2192. [CrossRef]

8. Li, J.; Wang, K.; Zhang, H. Flux-focusing permanent magnet machines with modular consequent-pole rotor. IEEE Trans. Ind. Electron. 2020, 67, 3374-3385. [CrossRef]

9. Li, J.; Wang, K.; Liu, C. Torque improvement and cost reduction of permanent magnet machines with a dovetailed consequent-pole rotor. IEEE Trans. Energy Convers. 2018, 33, 1628-1640. [CrossRef]

10. Cao, R.; Su, E.; Lu, M. Comparative study of permanent magnet assisted linear switched reluctance motor and linear flux switching permanent magnet motor for railway transportation. IEEE Trans. Appl. Supercond. 2020, 30, 1-5. [CrossRef]

11. Amitkumar, K.S.; Thike, R.; Pillay, P. Linear amplifier-based power-hardware-in-the-loop emulation of a variable flux machine. IEEE Trans. Ind. Appl. 2019, 55, 4624-4632. [CrossRef]

12. Sun, W.; Li, Q.; Sun, L.; Zhu, L.; Li, L. Electromagnetic analysis on novel rotor-segmented axial-field srm based on dynamic magnetic equivalent circuit. IEEE Trans. Magn. 2019, 55, 1-5. [CrossRef]

13. Sprangers, R.L.J.; Paulides, J.J.H.; Gysen, B.L.J.; Lomonova, E.A. Magnetic saturation in semi-analytical harmonic modeling for electric machine analysis. IEEE Trans. Magn. 2016, 52, 1-10. [CrossRef]

14. Tapia, J.A.; Leonardi, F.; Lipo, T.A. Consequent-pole permanent-magnet machine with extended field-weakening capability. IEEE Trans. Ind. Appl. 2003, 39, 1704-1709. [CrossRef]

15. Gysen, B.L.J.; Ilhan, E.; Meessen, K.J.; Paulides, J.J.H.; Lomonova, E.A. Modeling of flux switching permanent magnet machines with fourier analysis. IEEE Trans. Magn. 2010, 46, 1499-1502. [CrossRef]

16. Ping, J.; Shuhua, F.; Ho, S.-L. Distribution characteristic and combined optimization of maximum cogging torque of surfacemounted permanent-magnet machines. IEEE Trans. Magn. 2018, 54, 1-5. [CrossRef]

17. Bao, J.; Gysen, B.L.J.; Lomonova, E.A. Hybrid analytical modeling of saturated linear and rotary electrical machines: Integration of fourier modeling and magnetic equivalent circuits. IEEE Trans. Magn. 2018, 54, 1-5. [CrossRef]

18. Cheng, M.; Chau, K.T.; Chan, C.C.; Zhou, E.; Huang, X. Nonlinear varying-network magnetic circuit analysis for doubly salient permanent-magnet motors. IEEE Trans. Magn. 2000, 36, 339-348. [CrossRef]

19. Zhu, Z.Q.; Pang, Y.; Howe, D.; Iwasaki, S.; Deodhar, R.; Pride, A. Analysis of electromagnetic performance of flux-switching permanent-magnet machines by nonlinear adaptive lumped parameter magnetic circuit model. IEEE Trans. Magn. 2005, 41, 4277-4287. [CrossRef]

20. Wang, M.; Zheng, P.; Tong, C.; Zhao, Q.; Qiao, G. Research on a transverse-flux brushless double-rotor machine for hybrid electric vehicles. IEEE Trans. Ind. Electron. 2019, 66, 1032-1043. [CrossRef]

21. Fitzgerald, A.E.; Kingsley, C.; Umans, S.D. Fitzgerald and Kingsley's Electric Machinery, 7th ed.; McGraw-Hill: New York, NY, USA, 2013.

22. Li, B.; Li, G.-D.; Li, H.-F. Magnetic field analysis of 3-dof permanent magnetic spherical motor using magnetic equivalent circuit method. IEEE Trans. Magn. 2011, 47, 2127-2133. [CrossRef]

23. Li, N.; Zhu, J.; Lin, M.; Yang, G.; Kong, Y.; Hao, L. Analysis of axial field flux-switching memory machine based on 3-d magnetic equivalent circuit network considering magnetic hysteresis. IEEE Trans. Magn. 2019, 55, 1-4. [CrossRef]

24. Fu, D.; Gong, J.; Xu, Y.; Gillon, F.; Bracikowski, N. Coupled circuit and magnetic model for a transverse flux permanent magnet linear motor. IEEE Access 2020, 8, 159274-159283. [CrossRef]

25. Yu, C.; Niu, S. Development of a magnetless flux switching machine for rooftop wind power generation. IEEE Trans. Energy Convers. 2015, 30, 1703-1711. [CrossRef]

26. Liu, G.; Ding, L.; Zhao, W.; Chen, Q.; Jiang, S. Nonlinear equivalent magnetic network of a linear permanent magnet vernier machine with end effect consideration. IEEE Trans. Magn. 2018, 54, 1-9. [CrossRef]

27. Shi, H.; Niguchi, N.; Hirata, K. Design and analysis of surface permanent magnet vernier linear motor based on air gap magnetic flux density distribution. In Proceedings of the 12th International Symposium on Linear Drives for Industry Applications, Neuchâtel, Switzerland, 1-3 July 2019. 